\title{
IMAGO DEI DETURPATUR: EL PECADO «NEFANDO» $O$ «CONTRA NATURA» EN EL ARZOBISPADO DE ZARAGOZA (SIGLOS XV-XVI)
}

\author{
POR \\ Migubl ÁNGel MOTIS DOLADER \\ Universidad de Zaragoza
}

\section{RESUMEN}

Estudio sobre la reacción de las autoridades eclesiásticas de los primeros siglos de la Edad Moderna sobre la doctrina y la persecución de las desviaciones sexuales en el obispado de Zaragoza.

\begin{abstract}
Study on the ecclesiastic authorities' reaction of the first centuries in the Modern Age about the doctrine and the persecution of the sexual deviations in the Zaragoza bishopric.
\end{abstract}

1. LA JUSTICIA ECLESIÁSTICA: ORDO MUNDI \& PAX SOCIETATIS

La multiplicidad jurisdiccional', consustancial a la estructura orgánica y política de los Estados del Occidente cristiano desde el Medievo, refrenda la desigualdad estamental, cuya última ratio reside en el imperativo del privile-

\footnotetext{
' Cfr. Miguel del Molino, Repertorium Fororum et Observantiarum regni Aragonum, una pluribus cum determinationibus Consilii Justitiae Aragonum, practicis atque cautelis eiusdem fideliter annexis, Cesaraugusta, 1585, sub voce ulurisdiction, fols. CXCVIIv.CC.
}

Actas del I Congreso de Historia de la Iglesia y el Mundo Hispánico Hispania Sacra, 52 (2000) 
gio $^{2}$. La Monarquía católica, que había llevado a cabo un proceso de concentración de poder, que se impondrá sobre los restantes resortes institucionales ${ }^{3}$, nunca persiguió la supresión de unas jurisdicciones que conformaban sus bases sociales y la razón de dicho poder; su tarea consistía en vigilar su funcionamiento y armonizarlas sobre la base del reconocimiento de las prerrogativas de sus miembros, resolviendo los conflictos que se derivaran del ejercicio de sus competencias ${ }^{4}$.

En una sociedad donde el incremento de los índices de litigiosidad nace de su morfología conflictual, y cuyos miembros están condenados a pleitear sin descanso, la Iglesia posee jurisdicción propia ${ }^{5}$, así como un aparato judicial específico y autónomo con respecto al secular, en virtud de su naturaleza ${ }^{6}$, tal y como postula el concilio vallisoletano de $1322^{7}$. Además de las disputas relacionadas o nacidas en el seno del estamento eclesiástico - ratione personae-, ejerce potestad intrínseca, ratione materiae, sobre las causas spirituales ${ }^{8}$, las causae spiritualibus annexae y las englobadas bajo la rúbrica ratione peccati, esto es, los asuntos relativos a la fe, la doctrina y la impartición sacramental, al igual que el castigo y corrección de las infracciones de la ley divina o de los preceptos de la Iglesia romana ${ }^{9}$. Asimismo, se incluye el juramento - por su

\footnotetext{
${ }^{2}$ Michael R. WeIsser, Crimen \& Punishment in early Modern Europe, Bristol, 1979, pp. $51-52$.

3 J. M. GARCIA MARIN, «En torno a la naturaleza del poder real en la Monarquía de los Austrias», Historia. Instituciones y Documentos, 11 (1984), pp. 115-116, y Salustiano DE DiOs, «Sobre la génesis y los caracteres del Estado Absolutista en Castillas, Studia Historica, III (1985), pp. 11-46.

4 Benjamín Gonzalez ALONSo, «La Justicia», en Enciclopedia de Historia de España, Madrid, 1988, vol. 2, p. 382; Jesús LALINDE ABaDiA, «Una ideologia para un sistema (La simbiosis histórica entre el iusnaturalismo castellano y la Monarquía Universal)", Quaderni Fiorentini, 8, pp. 57-75, y Antonio DOMÍNGUEZ ORTIZ, «La monarquía. Los poderes civiles y la Inquisición, un arbitraje difícil», Anuario de Historia del Derecho Español, LXVII (1997), p. 1587.

5 Paul Ourlac, «La jurisdiction ecclésiastique au Moyen Age», en Mémoires de la Société pour l'Histoire du Droit et des Institutions des Anciens Pays bourguignons, comtois et romands, 34 (1979), pp. 13-20.

6 Apud Francesco ZANCHIN DI CASTIGLIONCHIO, Chiesa e potere: studi sul potere costituente nella chiesa, Torino, 1992.

7 Federico AzNAR GIL, Concilios Provinciales y Sinodos de Zaragoza de 1215 a 1563, Zaragoza, 1982, p. 90.

8 "Iudex ecclesiasticus non habet iurisdictionem in laycos nisi in ordine ad spiritualia». José SESSE PINOL, Inhibitionum et Magistratus lustitiae Aragomum, Tractatus in quo de inhibitionibus et executione privilegiata (...) agitur; variae que iuris resolutiones practicae cum totidem decisionibus; nec non consuetudines Regno Aragonum ad iuris terminos redacta traduntur \& explanantur, Barcinonae, 1608, cap. $9 \S 2, n^{\circ} 13$.

${ }^{9}$ Francisco de Vitoria defiende que la potestad y la autoridad para juzgar la materia de fe y de costumbres en los juicios eclesiásticos es ajena a la civil, porque se ordenan a fines y bienes distintos. Enrique LlaMAS MARTINEZ, «De necessitate iudicis externi Ecclesiae: infalibilidad conciliar y papal en materia de fe y de costumbres según Pedro de Aragón (1584)», La Ciudad de Dios, Revista Agustinia$n a_{1}$ CCX (1997), pp. 51-52.
} 
rango de «sacramentum»-, la excepción de «re iudicata» y por razón de «consuetudo antiquas ${ }^{10}$, etc.

\section{LA DUALIDAD: DELITO-PECADO}

A partir del siglo XII, al amparo de un nuevo concepto de justicia surgido en la cultura jurídica del cristianismo, nacen unas categorías que imperarán hasta bien entrada la Edad Moderna que no cuentan en la determinación del orden social con una tradición de revelación única, sino con una cultura de textos o heteronomía contenida en distintos corpora y biblia ${ }^{11}$ : Corpus Iuris Civilis configurado con un derecho de tradición romanística- y la Biblia - la manifestación divina más inmediata ${ }^{12}$-, comunicados entre sí por el Corpus Iuris Canonici $^{13}$. A esta complejidad se añaden los usos consuetudinarios que, salvo su derogación expresa en las constituciones sinodales, se equiparan con el precepto legal ${ }^{14}$.

En el contexto de esta tradición cultural, «omnis legis transgresio facit dignum penae», imbricando el orden religioso y el jurídico, de ahí que el pecado no sea un asunto de estricta teología o moral, y que el delito no pertenezca a la esfera de la justicia, «sino ambos de ambas» ${ }^{15}$; en cierto modo, se criminaliza el pecado y se somete a un proceso de «pecaminosidad» al delito. Además, esta lex participa de distintos niveles: ley eterna, divina positiva, natural y humana.

${ }^{10}$ Francisco C. PACHECO, «Ley, costumbre y uso en la experiencia jurídica peninsular bajomedieval y modernas, en El Dret Comú i Catalunya, Barcelona, 1995, pp. 119-136.

"A. M. HespaNHA, "Una historia de textos", en Sexo barroco y otras transgresiones premodernas, Madrid, 1990, pp. 190-191.

12 Autoridad suprema que, amén de sus elementos canónicos y apócrifos, no debe entenderse como una fuente puramente jurídica. Guy LoBRICHON, «Gli usi della Bibbia», en Lo Spazio Letterario del Medioevo. L. Il Medioevo Latino, vol. I, Roma, 1992, pp. 524-26 y 538-541.

Su conocimiento era deficiente, pues en la práctica hasta los últimos siglos medievales no se realizó una traducción íntegra del texto sagrado. Jean LECLERQ, Les traductions de la Bible et la spiritualité médiévale, Leuven, 1979 , p. 269.

13 Jean PASsicos, «Approches pour une épistémologie et pour une herméneutique du Droit canoniquen, Archives de Philosophie du Droit, 38 (1993), pp. 65-72.

14 «Ay cosas que se fundan en lo hordenado por los Sagrados Canones, y otras, cuya firmeca estriva en la costumbre loable, introducida por la mayor parte del pueblo, con mimo de constituir derecho, uso publico, frequencia comun, tolerancia de los superiores y transcurso del tiempo... las costumbres en la forma dicha introducidas en nuestro arçobispado, o sea generalmente en todo el, o en algunos lugares particulares se observen respectivamente donde assi estuvesen introducida como leyesn. Constituciones Synodales... ordenadas por el Excmo. Sr. D. Antonio Ybáñez de la Riva Herrera, Zaragoza, 1697 , lib. III, tit. II, const. 1, p. 395.

${ }^{15}$ Bartolomé Clavero, «Delito y pecado. Noción y escala de transgresiones», en Sexo barroco y otras transgresiones premodernas, p. 66. 
Este patente paralelismo entre delito y pecado -con la consiguiente mixtificación de Derecho, Teología, religión y moral ${ }^{16}$ - es fruto de una enunciación teologicista que recrea nociones extraídas de la escolástica y la canonística en el contexto del mos italicus ${ }^{17}$. Tal inserción del delito en el campo de la moral se perfecciona en dos etapas: la primera promovida por la Escolástica moderada, cuyo exponente más destacado es Tomás de Aquino, mientras que la segunda, más radical, reposa en la Escolástica de los siglos XVI y XVII, donde destaca la figura de Domingo de Soto y Alfonso de Castro ${ }^{18}$. La continuidad de este corpus ideológico de la doctrina penalógica clásica perdura desde la Plena Edad Media hasta los albores de la Ilustración ${ }^{19}$, cuando en las décadas previas comienza a extinguirse en sectores muy selectos de intelectuales y juristas imbuidos de un pensamiento emancipador ${ }^{20}$, decantado más tardíamente en los territorios hispánicos ${ }^{21}$.

16 Olivier ECHAPPE, «Délit et péché. Le mal vu par les canonistes médiévaux», en Le mal et le diable. Leur figures a la fin du Moyen Age, Paris, 1996, p. 247.

17 Melchiorre ROBERT1, «"Delictum" e "peccatorum" nelle fonti romane e cristiane», en Studi di Storia e Diritto in onore di Carlo Calisse, vol. I, Milano, 1940, pp. 159-76.

Bártolo, glosando el Codex, 1,2,1 a propósito del criterio de pecado, sefiala: «aut loquimur in spiritualibus et pertinentibus ad fidem et stamus canoni (...); aut loquimur in temporalibus, et tunc in terris subiectis Ecclesiae, et sine dubio stamus decretalibus; aut in terra subiectis Imperio, et tunc, aut servare legem est inducere peccatum... et tunc stamus canonibus (...); aut non inducit peccatum (...) et tunc stamus legi». Cit. António Manuel ESPANHA, Panorama histórico da cultura juridica europeia, LisboaMacau, 1994-95, p. 27.

${ }^{18}$ Este último, en su obra De potestate legis poenalis libri duo, escribirá: «Illi [los juristas] vero teologis concedant de illarum potestate atque iustitia disputare quia illa sine legis divinae cognitione nequaquam recte intelligi potestı. Cfr. Santiago CASTLLo HeRNÁNDEZ, Alfonso de Castro y el problema de las leyes penales o la obligatoriedad moral de las leyes humanas, Salananca, 1941; Marcelino Rodriguez MOLINERo, "Teoría de Fray Alfonso de Castro en torno a la ley penal», Liceo Franciscano, 4 (1958), pp. 351-375 y Origen español de la ciencia del derecho Penal. Alfonso de Castro y sus sistema penal, Madrid, 1959.

19 António M. HeSPANHA, «Una historia de textos», p. 194.

${ }^{20}$ Bien es cierto que la herencia del Humanismo juridico tras la crisis del Quinientos pernitirá que «le opere sulla "topica" legale, sulla "ars", "methodus" e cosi via, intendono ricostituire su nouve basi il sistema giuridico, e in particolare i suoi fundamenti -quelli che sono poi decisivi anche in sede di formaziones dei giovani giuristi». Mario AsCHERI, «I giuristi, l'umanesimo e il sistema giuridico dal Medioevo alla'Età Modernan, en El Dret Comú i Catalunya. Actes del II. Simposi Internacional, p. 155. Cfr. etiam Raoul CAENEGeM, Judges, legislators and Professors. Chapters in European Legal History, Cambridge, 1987, y Mario Ascher, I signori del diritto. Giudici, legislatori e professori nella Storia exropea, Milano, 1991.

${ }^{21}$ PaCHeco, El Código penal concordado y comentado, vol. I, Madrid, 1856, vol. I, p. XXXV.

A principios del siglo XVII se quiebra el pensamiento teocrático al triunfar las tesis belarminianas, abandonando los postulados del poder directo de la jerarquía eclesiástica sobre cuestiones temporales. Alberto DE LA HERA, «La "Monarquía católica" espafiola», Amuario de Historia del Derecho Español, LXVII (1997), p. 663.

Actas del I Congreso de Historia de la Iglesia y el Mundo Hispanico

Hispania Sacra, 52 (2000) 
El delito canónico - crimen, delictum, scelus ${ }^{22}$ - queda determinado en su carácter externo así como en su componente de transgresión informada por los valores morales y espirituales del acervo común ${ }^{23}$, pero también por una serie de factores estructurales como el discurso de poder, el concepto de familia y honor personal, etc. ${ }^{24} \mathrm{En}$ su esfera de acción no se incluye el pensamiento «cogitationis poenam non patiatur ab homine, sed a Deo»-, dado que «Ecclesia non iudicat de occultis ${ }^{25}$; no hay intimidad sino intimidación, porque se sirve de la conciencia al solo efecto de su eficacia instrumental ${ }^{26}$.

El tratamiento dual del pecado - que no remite a una conciencia individual- aborda una conducta transgresora severa e identifica el responsable de la transgresión - el pecador-, afectando internamente al Derecho e interviniendo en el orden social. Entre pecado y delito coexisten componentes tautológicos que los indiferencia - (hic dicit peccatum, idem vocat delictum)-, aunque la doctrina incida en la necesaria deliberación de la comisión del pecado - «forum conscienciae»- como elemento distintivo, "declinare a bono est delictum, et peccatum est facere malum». Existe unidad radical y de fondo; se impone una relación biunívoca y simétrica: delito es pecado, pecado es delito. Bajo este paradigma no hay una religión respecto a la que se definan los pecados y un derecho en cuya relación se determinen los delitos, ni una potestad eclesiástica de un lado estableciendo los pecados y un poder político de otro haciendo lo propio con los delitos. Religión y Derecho concurren de forma efectiva en el ordenamiento; el segundo primordialmente disciplina, la primera ante todo incultura. Conjuntamente ordenan, pero la religión opera a unos niveles básicos inalcanzables para el Derecho, por lo que si nos redujésemos al orden jurídico ignoraríamos elementos vitales del propio ordenamiento ${ }^{27}$.

22 Ángel PARIENTE, «Notas sobre el vocabulario jurídico latino: 1. "crimen"; 2. "cluens: cliens"; 3. "Arbier"; "Iurare"", Anuario de Historia del Derecho Español, XV (1946), pp. 932-1009.

Las fuentes judiciales emplean dentro del mismo campo semántico los términos crimen, delito y exceso. Nicole GoNTHER, Le chôtiment du crime au Moyen Age, Rennes, 1998, p. 34. De hecho, algunos procesos homologan los «criminibus excessibus» con los «delictis». A. Dioc. Z. [Archivo Diocesano de Zaragoza], Sección Histórico Jurídica, Procesos Criminales, C-5/5.

${ }^{23}$ Las leyes humanas dejan ciertos pecados impunes por la imperfección del hombre. Tomás de Aquino, Summa Theologiae, 2-2, q. 78, art. 1, ad. 3.

24 Johan K. BrACKETT, Criminal Justice and Crime in late Renaissance Florence, 1537-1609, New York, 1992, p. 100.

${ }^{25}$ Decretales, lib. I, tít. 3, cap. 33 (Inocencio III). Sobre este mismo aforismo: Antonio de SousA (O. P.), Aphorismi Inquisitorum in quatuor libros distributi, Lugduni, 1669, 1ib. 3, cap. 33, núms. 5 y 7, y Cesare CARENA, Tractatus de Officio Sanctissimae Inquitionis et modo procedendi in causis fidei in tres partes divisus, Lugdumi, 1659 , pars 3 , tit. IX, \& 15, $n^{\circ}, 67-68$.

${ }^{26}$ Bartolomé CLAVERo, «Delito y pecado. Noción y escala de transgresiones», pp. 62-63.

27 Bartolomé ClaVero, «Beati Dictum: Derecho de linaje, economía de familia y cultura de orden", Anuario de Historia del Derecho Espaßhol, LXIII-LXIV (1993-94), pp. 128-129, y «De la religión en el Derecho, historia mediante», Quaderni Fiorentini, 15 (1986), pp. 531-549. 
No todas las acciones punibles -malas per se-- son catalogadas como delito - un pecado sólo será delito si afecta al ordo mundi y a la pax societa$t_{i s^{28}}$ - pues existen otras que se ponderan como meras contravenciones de la norma. No en vano, los teólogos aprecian que la ley penal tiene una naturaleza bifronte tanto moral -imperativo de lo justo y prohibición de los injusto- como penal stricto sensu — susceptible de la imposición de una pena-; la ley obliga externamente con una pena temporal y moralmente bajo una sanción de conciencia. Las consecuencias directas consistirán en la ampliación del marco delictivo y su graduación; principio de la personalidad de la pena; extensión de la responsabilidad penal sobre otros actores distintos de los ejecutores materiales del ilícito; consideración de las circunstancias que rodean el delito; retribución como fin primordial de la pena; intimidación y ejemplaridad $^{29}$.

\section{DELICTA CARNIS: «YERROS DE LUXURIA»}

La cosmogénesis medieval aprecia la vida del cuerpo como una perfecta homotecia o proyección de su contenido espiritual, en una peregrinación iluminada por los sentidos; es un «modo» de glorificar a Dios y no un vehículo de deleites terrenales ${ }^{30}$. De ahí la vigilancia ejercida frente a las deshonestidades de la carne, mero envoltorio que puede atentar contra esa vocación inmanente de trascendencia ${ }^{31}$, y la necesidad de constrefirir cualquier actividad sexual lícita a la procreación, rigurosamente codificada, frente a la réproba búsqueda del placer, concebida como regula turpe $e^{32}$.

\footnotetext{
28 Un cura concubinario es un pecador, pero no se convertirá en delincuente salvo que lo practique con notoriedad. André LalNGu y Arlette Legrbre, Histoire du Droit Pénal. II. La procédure criminelle, Paris, s. a., p. 47

29 Jesús Lalinde ABadia, Las Culturas represivas de la Humanidad, Zaragoza, 1992, p. 814.

${ }^{30}$ I Corintios, 6,20 y 13.

31 «Que apaga el incendio del apetito torpe de los deleytes». Constituciones Synodales... hechas por fray Juan Cebrián, Zaragoza, 1656, fol. 12v. En este sentido, «alia quoque ratio crimen nobis contradicit amoris. Nam, quum omnia crimina ipsam animam tantum de sui soleant inquinare natura, istud crimen solum animam simul cum corpore foedat). Andrés CAPELLAN, De amore (Tratado sobre el amor). Barcelona, 1990, p. 372.

32 Según la terminología de la época, la expresión solicitare, provocare, allicere o tentare uad turpias, identifica la provocación que ha dado lugar a acciones concupiscentes o venéreas consumadas, procedentes de la puesta en práctica de los instrumentos o mecanismos adecuados. Juan Antonio ALEJANDRE, El veneno de Dios. La Inquisición de Sevilla ante el delito de solicitación en confesión, Madrid, 1994, p. 12.
} 
Asistimos a la concreción de un pecado provocado por la lujuria - la libido es la concupiscencia de lo sexual- ${ }^{33}$, siempre de naturaleza mortal y «lepra incurable» ${ }^{34}$ opuesta al espíritu ${ }^{35}$. Por el contrario, la valoración que la sociedad efectúa de las relaciones sexuales dista de un sentimiento de culpabilidad, porque juzga que no son necesariamente reprochable. De hecho, una corriente de pensamiento extendida en amplios sectores de la sociedad, entre sus miembros más cultivados intelectualmente, entiende que la fornicación simple es un pecado venial, activando un mecanismo consciente de justificación de una realidad asumida ${ }^{36}$, alimentando el delito de las «proposiciones»" ${ }^{37}$

En un ensayo ponderativo - intuitivo- de la gravedad de estos pecados debemos partir de la premisa de que el varón está llamado a colaborar con Dios en la tarea de la Creación continua, quien le infundió en el semen la potencia generatriz de nuevos $\operatorname{seres}^{38}$, asignando a la mujer un papel pasivo de mero receptáculo ${ }^{39}$. El pecado se incrementa conforme las criaturas se alejan de una honesta colaboración en la obra de Dios - el placer no tiene existencia reconocida, sólo es válido per accidentem, como factor coadyuvante-, infeudándose en el apetito egoista y estéril ${ }^{40}$.

Dentro de los delicta carnis contenidos en el sexto mandamiento del Decálogo, la fornicación simple apenas es un pecado grave, al amparar toda conducta heterosexual realizada con rectitud -en el sentido de natural-, sin poner obstáculos a la procreación, fin objetivamente perseguido, pero sin hallarse unidos por el vínculo del matrimonio, habida cuenta de que yace «suelto con suel-

33 Li vitit della carne y los placeres no naturales reciben tratamiento especifico en Tomás de Aquino, Summa Theologiae, § De las pasiones, 1-2, q. 31-48. Cfr. etiam J. DecumeAu, Le péché et la peur: la culpabilisation en Occident (XIIIe-XVIIIe siècles), Paris, 1983, pp. 238-246.

34 J. Delumeau, Le péché et la peur: la culpabilisation en Occident (XUIe-XVIIJe siècles), p. 470.

35 Gálatas, 5,16-17.

${ }^{36}$ Isabel TESTÓN NúŇEZ, «El pecado y la came durante el período modemon, en Pecado, Poder y Sociedad en la Historia, Valladolid, 1992, pp. 127-128, y Bartolomé BENNASSAR, Los españoles. Actitudes y Mentalidades, Barcelona, 1974, pp. 169-170.

${ }^{37}$ A modo de ejemplo, el tribunal inquisitorial de Granada procesará a 287 personas durante el siglo XVI, y a 100 a lo largo del siglo XVI, no desapareciendo formalmente hasta 1681. Flora GARcla IVARs, La represión en el tribunal inquisitorial de Granada. 1550-1819, Madrid, 1991, pp. 42-43.

38 James A. BRUNDAGE, "Carnal delight: canonistic theories of sexuality", en Proceedings of the Fifth International Congress of Medieval Canon Law, Città del Vaticano, 1980, pp. 361-85.

39 En el Medievo se establecerá una clara afinidad entre la lujuria y ula humedad femeninas. Cuando se desarrolle el mito de la bruja, la sociedad proyectará su temor a la mujer y a la muerte. Claude KAPPLER, Monstruos, demonios y maravillas a fines de la Edad Media, Madrid, 1986, p. 300.

40 Se invocan fundamentos bíblicos: a) bestialismo: Exodo, 22,19; Deuteronomio, 27,21; Levítico, 18,23 y 20,15-16; b) homosexualidad: Levítico, 18,22, 20,13; Deuteronomio, 23,18; Romanos, 1,26-7 y I Corintios, 6,9 . 
tas, siempre y cuando no esté implicado un clérigo in sacris; le sigue el estupro, entendido como una relación sexual entre hombre y doncella -algunos penitenciales contemplan «quando yaze omne con virgen o con viuda»- con la concurrencia de dolo; reviste mayor gravedad el adulterio - «quando yaze omne con muger de otro»- - , porque la ofensa se infiere al marido ultrajado y al vínculo sacramental; le sigue el incesto-estupro -con un meticuloso examen de la proximidad parental - que en obediencia con los parámetros antropológicos sería el más pernicioso; incrementando un grado nuestra escala se sitúa el «crimen sacrílego» practicado con una «esposa espiritual de Dios», es decir, con una monja, pero no el realizado por un clérigo. En fin, el acto scontra natura), que reviste la gravedad supina ${ }^{41}$.

En síntesis, este catálogo de pecados ${ }^{42}$, si nos atenemos a la axiología teológico-moral, se dividen en dos especies: en la primera se incluyen los pecados «naturales», articulados en la fornicación simple (amancebamiento) y la cualificada (adulterio, incesto, relaciònes sacrílegas, etc.); mientras que en la segunda se tipifican los pecados "contra naturaleza», entre los que se nominan la polución y el onanismo, y en cuya escala más execrable se sitúa la sodomía y la bestialidad ${ }^{43}$. Entender este complejo «palimpsesto» como meramente sexual sería caer en un sociologismo desligado de la mentalidad de la época ${ }^{44}$, cuyo alcance

${ }^{41}$ Francisco TOMÁS Y VALIENTE, «El crimen y pecado contra natura», en Sexo barroco y otras transgresiones premodernas, pp. 36-37.

«De luxuria demandara asi: ¿feziste fornication simple, que es quando alguno suelto conosce a alguna suelta, e feziste stupro, que es yazer con virgen, o feziste adulterio, que es yazer con casada?, ¿faziste ynçesto, que es conoş̧er parienta o cuñada o alguna de religion?, ¿pecaste contra natura, que es quando otramente conosçe la muger que non deva segunt natura? Pero non deve demandar en espeçial las maneras; e demandandole si le acaesçio pulluçion preguntele comom. José Luis MARTiN y Antonio Linage Conde, Religión y Sociedad Medieval El Catecismo de Pedro de Cuéllar (1325), Salamanca, 1987, p. 200.

${ }^{42}$ La actividad procesal del tribunal eclesiástico de Coria tuvo como uno de los objetivos prioritarios en los siglos XVI y XVII la urepresión sexual», que alcanzb casi un tercio de sus actuaciones. Isabel TESTón NúNEZ, «El pecado y la carne durante el período moderno», p. 126.

El mismo proceder al advertido en la justicia criminal secular, derivado de su diversidad y complejidad Pablo PÉREZ GARCiA, La comparsa de los malhechores. Valencia. 1479-1518, Valencia, 1990, p. 101]. Inclúyense también los tribunales del Santo Oficio. Henry KAMEN, «Notas sobre brujeria y sexualidad y la Inquisición», p. 235.

${ }^{43}$ Para los moralistas pecar con soltera es simple fornicación; con una casada, adulterio; con una doncella, estupro; con un pariente, incesto; y con una religiosa, adulterio espiritual. Luis DE GRANADA, Memorial de la vida cristiana, pars 1, tractatus 2, cap. 1. Este clérigo intachable fue acusado de erasmismo en 1559, incluyéndose su Guía de Pecadores en el índice de obras prohibidas por la Inquisición. J. M. Balcells, Fray Luis de Granada. Guía de pecadores, p. xxv.

44 Julio Caro BarojA, Las formas complejas de la vida religiosa (Siglos $X V I y$ XVII), p. 53.

Actas del I Congreso de Historia de la Iglesia y et Mundo Hispánico

Hispania Sacra, 52 (2000) 
y significado se resiente de la ausencia de estudios sistemáticos sobre la estructura y moral familiar ${ }^{45}$.

\section{CRIMEN ATROCISSIMO: OFFENSA DEI ET TOTIUS NATURAE}

El pecado «nefando", realizado por un ser creado a imagen y semejanza de Dios, es el «crimen» por antonomasia, sin adjetivaciones ${ }^{46}$, cuya sola mención repugna ${ }^{47}$; empero, no es conceptum unicum, porque sus connotaciones dependen del entramado social, ideológico y mental en que se desenvuelve ${ }^{48}$.

Los delitos enormes y abominables, producto de «actos desaforados» y las «posiciones no naturales» impiden la «emisión seminal ordenada» o el «coito natural» que, bajo un prisma neoplatónico, teológica y teleológicamente es un acto intrínseco generado para la procreación-reproducción dentro de su especie. No se trata de una mera fornicación extramatrimonial, de dolo o de ofensa a un sacramento: es Dios el ofendido directamente, sin intermediación ni paliativos, porque se altera su cosmogénesis, se perturba el orden natural - superior al social-y se interrumpe el sagrado eslabón -el alma- de la Creación divina ${ }^{49}$.

Para Tomás de Aquino, autoridad preeminente e indiscutida, todas las cosas sin excepción han sido creadas por Dios con un fin específico. Así, los genitales existían para la reproducción, y cualquier uso no conducente a tal efecto es un acto de rebelión contra los deseos divinos, léase, cualquier método de contracepción $^{50}$. Dentro de esta valoración, la única técnica moralmente aceptable en

45 No estamos en condiciones de analizar, así, el impacto real de la Inquisición sobre la sexualidad. Además «la đocumentación episcopal es mucho más fiable en estos aspectos». Henry KaMEN, «Notas sobre brujería y sexualidad y la Inquisicións, en Inquisición espanola y mentalidad inquisitorial, Barcelona, 1984, p. 235.

46 Patricia H. LABalme, «Sodomy and Venetian justice in the Renaissance", Revue d'Histoire du Droil, 52 (1984), pp. 217-54.

47 Porque «non tan solamente es mala de fablar mas aun ante es mala de asmarn. José Luis MARTíN y Antonio LINAGE Conde, Religión y Sociedod Medieval. El Catecismo de Pedro de Cuéllar (I325), p. 179.

48 En la Italia renacentista, los estatutos de Luca, publicados en el siglo XV y glosados en la siguiente centuria, lo aplican a actos sexuales contra natura exclusivamente masculinos, incluyendo masturbación y sexo oral. En Venecia, sin embargo, la legislación contemporánea se refiere explícitamente a los actos sexuales mantenidos entre hombres o entre mujeres, lo que no impide que algunos pensadores dominicos, a mediados del siglo XVI, retornen a la argumentación homoerótica masculina. Nicholas DAVIDSON, "Theology, nature and the law: sexual sin and sexual crime in ltaly from the fourteenth to the seventeenth centurym, en Crime, Society and the Law in Renaissance Italy, Cambridge, 1994, p. 76.

49 Francisco TOMAs y VALIENTE, «El crimen y pecado contra natura", pp. 36-38.

50 Entre los métodos «mecánicos» se practicaba el «coitus interruptus»; las posiciones prohibidas «extra vas» o «in vas» (coito anal, bucal o crural); el «amplexus reservatus»; el preservativo o condón; 
la "conjuncio sive coitus» era la "postura del misionero», asociada con la superioridad ontológica del hombre respecto a la mujer ${ }^{51}$.

De la praxis procesal - las disputas jurisdiccionales redundan en beneficio del tribunal eclesiástico, a pesar de que la causa fuera conocida a priori en instancia secular ${ }^{52}$ - se deduce que este delito es contemplado como pecado de sensualidad y no tanto, frente a lo que sucede en la Inquisición, pecado de error con contenidos heréticos ${ }^{53}$. La alarma social producida conduce, como señalo más adelante, a la revocación de ciertas garantías procesales - aunque para la prueba plena no sea suficiente el testium unicum como sucede con la lesa majestad y la herejía ${ }^{54}$ - y a una extrema severidad en la sanción, admitiéndose, incluso, el tormento de un noble o un clérigo ${ }^{55}$.

\subsection{Homofilia y sodomía: «apetito torpe»}

La sodomía es un pecado poliédrico y multidireccional, pues atenta contra Dios, la dignidad de uno mismo y el prójimo, constituyendo un grave y condenable atentado contra la fe y la moral ${ }^{56} \mathrm{Si}$ la relación se establece entre personas del mismo sexo se realiza una sodomía perfecta o típica ${ }^{57}$, mientras que si se trata de una relación heterosexual contra natura, cuando el varón «otramente conosçe la muger que non deva segunt natura» - coito anal, sexo oral o mediante procedimientos artificiales ${ }^{58}$-, se califica de imperfecta 0 atípica ${ }^{59}$.

\footnotetext{
la continencia periódica; la hipofecundidad; y los movimientos y la higiene postcoital. Jean Claude BOLOGNE, La Naissance Interdité. Stérilité, avortement, contraception au Moyen Age, s. L., 1988, pp. 145-157.

${ }_{51}$ Manuel NúNEz Rodriguez, Casa, calle, convento. Iconografia de la mujer bajomedieval, Santiago de Compostela, 1997, p. 258, y Nicholas Davidson, Theology, Nature and the Law: Sexual Sin and Sexual Crime in Italy from the fourteenth in the seventeenth century, pp. 77-79.

${ }_{52}$ A. Dioc. Z., Sección Histórico Juridica, Procesos Criminales, C-19/40 (1564).

53 Bartolomé BENNASSAR, «El modelo sexual: la Inquisición de Aragón y la represión de los pecados "abominables" ", en Inquisición española: poder político y control social, Barcelona, 1981, p. 296.

${ }_{54}$ Francisco TOMÁs Y VALIENTE, El derecho penal en la Monarquía Absoluta, Madrid, 1969, p. 228.

55 Francisco TomÁs Y VALIENTE, "El crimen y pecado contra natura», pp. 41-42 y 44.

${ }^{56}$ Cfr. Glenn OLSEN, W., «St. Anselm and Homosexuality», Anselm Studies, 2 (1988), pp. 93-141; John BALDWN, W., «Five discourses on desire: sexuality and gender in northern France around 1200"s, Speculum, 66 (1991), pp. 797-819 [referido a Johan Bodel, Andreas Capellanus, Jean Renart, Petrus Cantor y el Salernitano], y Joseph PEQUIGNEY, «Sodomy in Dante's Inferno and Purgatorio», Representations, 36 (1991), pp. 22-42.

57 «Sodomiticio dizen el pacado en que caen los omes yaziendo unos con otros, contra natura e costumbre naturaly. Las Partidas, 7,21.

${ }^{58}$ Algunos penitenciales, como el atribuido a Hincmar de Reims, refiriéndose a las mujeres hablan de ciertos instrumentos — (quasdam machinas»- utilizados en operaciones «diabólicas» para excitar

Actas del I Congreso de Historia de la Iglesia y el Mundo Hispánico

Hispania Sacra, $52(2000)$
} 
La práctica totalidad de los procesos obedecen al primer supuesto, lo que no impide que algunos varones amenazaran «ad uxorem propiam vel ad aliam quamlibet mulierem» por no brindarse a las «deshonestidades» que les proponían en la intimidad de la alcoba ${ }^{60}$.

La doctrina distingue dentro de la (homosexualidad» -el «lesbianismo" ${ }^{61}$ es procesalmente silenciado ${ }^{62}$ - la modalidad con penetración o la simple masturbación. La detección penal del onanismo ${ }^{63}$, por su propia naturaleza, reviste notable dificultad si no concurren determinadas circunstancias. De ahí que uno de los casos excepcionales sustanciados es fruto de la visita pastoral girada el año 1584, cuando los habitantes de La Condoñera -población de reducidas dimensiones donde el secreto es dificil de mantener--, a solicitud del prelado, denuncian que uno de sus convecinos practicaba esta actividad, designada bajo la expresión «hacerse la puñeta». Su procesamiento sólo fue posible porque la publicidad y el escándalo desbordaron la esfera privada, ante su incontenible tendencia a realizarla con otros hombres, modalidad conocida popularmente como la «zaragozana) ${ }^{64}$.

Estas graves desviaciones de la conducta, agravadas desde fines de la Edad Media, de forma alarmante en la península italian ${ }^{65}$, obedecen, según algunas hipótesis, tanto a un contexto de represión - amalgamado con una feroz misoginia $^{66}$ - como a motivos psicológicos y sociológicos animados por el paulatino retraso en alcanzar el estado marital, debido a la carencia de medios económicos para firmar las capitulaciones ${ }^{67}$.

el apetito sexual. J. Boswell, Christianity, Social Tolerance and Homosexuality. Gay People in Western Europe from the Begining of the Christian Era to the Fourteenth Century, Chicago, 1980, p. 204.

s9 "Se incluye también a las mujeres tanto cuando una con otra haga contra natura como cuando varon con hembra haga el coito contra natura». Gregorio López, glosa «omes» 7,21,1.

${ }^{60}$ A. Dioc. Z., Sección Histórico Juridica, Procesos Criminales, C-22/13 (1600).

61 Codificado desde muy temprano en los penitenciales. Pierre J. PAYER, Sex and the Penitentials, Toronto, 1984, p. 138, y Marc A. MEYER, «Early Anglo-Saxon Penitential and the position of Women», Haskins Society Journal, 2 (1990), pp. 47-61.

${ }^{62}$ No supera ef $1,3 \%$ de la estadística registrado en el tribunal inquisitorial de Valencia. Stepher HALICZER, Inquisition and Society in the Kingdom of Valencia (1478-1834), Berkeley, 1990, p. 304. Asimismo, Ricardo García CARCEL, Herejia y Sociedad en el siglo XVI. La Inquisición de Valencia (1530-1609), Barcelona, 1980, p. 290, y Juan BLAzquez Miguel, La Inquisición en Cataluña. El Tribunal del Santo Oficio de Barcelona. 1487-1820, Toledo, 1990, p. 203.

${ }^{63}$ Se entiende como una specie de autofornicación: «propriis membris se ipsum violaverit» o «per se ipsum fornicaverits. Pierre J. PAYER, Sex and the Penitentials, pp. 46-47.

${ }^{64}$ A. Dioc. Z., Sección Histórico Jurídica, Pracesos Criminales, C-27/17 (1584),

${ }_{65}$ Me refiero a Florencia. Cft. «Società maschile e sodonia. Dal declino della "polis" al Principato", Archivio Storico Italiano, 150 (1992), pp. 115-138.

${ }_{66}$ Ricardo GARCfA CARCEL, Herejla y Saciedad en el siglo XVI. La Inquisición de Valencia (15301609), p. 288.

67 J. Chiffoleau, Les Justices du Pape, Paris, 1984, p. 192.

Actas del I Congreso de Historia de la Iglesia y el Mundo Hispánico Hispania Sacra, $52(2000)$ 
La sodomía y los delitos conexos, en cuanto «crimen pessimo», pueden atribuirse a diversas jurisdicciones en razón del estado, por su naturaleza de mixti fori. Algunos autores aseguran que dentro de los territorios hispánicos sólo en Castilla se sujetaban a los tribunales eclesiásticos o civiles, salvo si estaban involucrados eclesiásticos que no fueran ministros o familiares del Santo Oficio, para silenciar el oprobio estamental que ello suponía ${ }^{68}$.

En la Corona de Aragón su conocimiento dependería de la Inquisición, tras la provisión de una pragmática fernandina de $1505^{69}$-entrafiando la relajación al brazo secular ${ }^{70}$-, seffalándose más tarde mediante un Breve papal de 1524 dictado por Clemente VII, que debería procederse siempre «iuxta leges seculares vel municipalia estatuta» ${ }^{71}$. A este respecto, los fueros aragoneses garantizan que el prendimiento no produce confiscación cautelar de bienes ${ }^{72}$. Sin embargo, los procesos analizados procedentes del archivo diocesano ${ }^{73}$ contradicen la exclusividad aducida. Ello no significa que cuantitativamente la balanza no se incline en favor del órgano inquisitorial, como se demuestra en la tabla inferior, donde, ciñéndome al periodo $1541-1580$, frente al centenar de reos indiciados por éste, el oficial arzobispal conoce sólo nueve, lo que se traduce en un $10 \%$ del universo delictual ${ }^{74}$ (véase cuadro de página siguiente).

Se colige de estos datos que las actuaciones jurisdiccionales son casi idénticas en su vertiente cronológica, aunque la curia episcopal registra un retraso de una década, dado que la primera sentencia recae en 1560 , precisamente cuando se recrudece la persecución inquisitorial. Esta evolución no responde a una súbita eclosión ni a un drástico cambio en la mentalidad o conducta sexual de

\footnotetext{
68 Francisco ToMAs Y VALIENTE, «El crimen y pecado contra naturas, p. $5 \mathrm{I}$.

69 Paralelamente, el Papa Julio II extendía su ámbito de actuación allende la herejía, al atribuirle el conocimiento de las causas contra la usura. Gonzalo MARrínez DíEZ, Bulario de la Inquisición Española hasta la muerte de Fernando el Católico, Madrid, 1998, doc. 82.

${ }^{70}$ Lo cierto es que no se aplicó sistemáticamente, como lo demuestran los recuentos efectuados entre 1566 y 1620 en los tribunales de Barcelona $(2,3 \%)$,Valencia $(13,7 \%)$ y Zaragoza $(19,1 \%)$, sobre un universo de 371 supuestos. Raphäel CARRASco, "Le châtiment de la sodomie sous l'Inquisition (XVI-XVIIe siècle)", en Mentalités. Histoire des cultures et des sociétés. Violences sexuelles, Paris, 1989 , p. 61 .

71 AHN [Archivo Histórico Nacional de Madrid], Sección Inquisición, lib. 326, fols. 150-150v.

72 Pascual Savall y Santiago Penen, Fueros, Observancias y Actos de Cortes del reino de Aragón, Zaragoza, 1991, vol. II, p. 52b.

73 Cfr. Miguel Ángel Motts Dolader e Isabel Falcón Pérez, aDocumentación judicial del Arzobispado de Zaragoza en el Antiguo Régimeny, en Reunión Científica Internacional. Valoración del Estado de las Fuentes Históricas, Juridicas y Literarias hispanas ante el siglo XXI, Barcelona, 1996 (en prensa).

74 Adviértase que la serie de 1551-1560 está incompleta. Bartolomé BENNASSAR, «El modelo sexual: la Inquisición de Aragón y la represión de los pecados "abominables"», pp. 301-302. Los datos han sido procesados a partir de AHN, Sección Inquisición, lib. 988 y 989.
}

Actas del I Congreso de Historia de ta Iglesia y el Mundo Hispánico

Hispania Sacra, 52 (2000) 


\begin{tabular}{|c|c|c|c|}
\hline Periodo & Inquisición & Iglesia & Total \\
\hline $1541-1550$ & 16 & 0 & 16 \\
\hline $1551-1560$ & 7 & 1 & 8 \\
\hline $1561-1570$ & 33 & 5 & 38 \\
\hline $1571-1580$ & 44 & 3 & 47 \\
\hline $1581-1590$ & $(\ldots)$ & 3 & $(\ldots)$ \\
\hline $1591-1600$ & $(\ldots)$ & 1 & $(\ldots)$ \\
\hline
\end{tabular}

sus habitantes, aunque la represión del Santo Oficio esté determinada por criterios políticos o metajuridicos, sino por las directrices emanadas del Concilio de Trento en defensa del matrimonio sacramentalizado. Además, guarda una perceptible concordancia la proporcionalidad entre los procesados, ya que tanto en la jurisdicción inquisitorial como en la episcopal se aprecia una relación de 5 a 3 , es decir, los delitos por sodomía suponen un $64 \%$ y un $61 \%$, respectivamente, de las causas incoadas por nefandidad ${ }^{75}$.

Es un delito de implantación urbana, concentrándose casi un $40 \%$ de los casos en la capital del reino ${ }^{76}$, conferidora de un mayor grado de anonimato y diversidad social, con un segmento apreciable de población flotante de muy variada condición, aunque también figuren agricultores en determinados contextos ${ }^{77}$. Como tónica, los culpables acreditan edad adulta ${ }^{78}$-incluyendo padres de familia ${ }^{79}$-, lo que no significa que no concurran esporádicamente muchachos que

75 Dentro de los delitos discemidos por la Curia arzobispal de Zaragoza, el pecado abominable durante el periodo 1560-99 representa un 3,2\%. Miguel Ángel MoTIs DOLADER e Isabel FALCón PÉREZ, Procesos criminales del Arzobispado de Zaragoza (ss. XV-XVIII): Regesta, estudio e indices, Zaragoza, 1999 (en prensa).

${ }^{76}$ A. Dioc. Z., Sección Histórico Jurídica, Procesos Criminales, C-19/1 (1560), C-19/10 (1562), C-52/13 (1562), C-52/1 (1563) \& C-76/18 (1599).

En lo que respecta al distrito barcelones, se adscriben a su sede capitolina un $45 \%$. Juan BLAZQUEZ Miguel, La Inquisición en Cataluña. El Tribunal del Santo Oficio de Barcelona. 1487-1820, p. 207.

7 A. Dioc. Z., Sección Histórico Huridica, Procesos Criminales, C-30/33 (1570).

78 A tenor de la actuación del Santo Oficio en Valencia aparece la siguiente radiografia: clérigos y asimilados $(19,1 \%)$, grupos dominantes $(5,5)$, mundo laboral $(36,4 \%)$, sirvientes $(18,6 \%)$, población nómada $(17,7)$, otros $(2,3 \%)$. Raphăel CARrasco, «Le châtiment de la sodomie sous l'Inquisition (XVI-XVIle siecle)"), pp. 62-63.

${ }^{79}$ Los testigos lo describen como un hombre de mediana estatura, barba entrecana, que vestía uma ropilla y «çaragüellos» verdes, botas negras, capa y un sombrero con muchas figuras, como los romeros 
rayan los veinte años en el medio rural, de bajo nivel de instrucción, a los que se tilda de «viciosos, glotones [y] descuydados» ${ }^{80}$. La inclinación homoerótica muestra en sus episodios una acusada e indefectible debilidad por niños y adolescentes de corta edad (entre seis y quince años ${ }^{81}$ ) o, subsidiariamente, muchachos jóvenes ${ }^{82}$. En definitiva, la relación actor-víctima no es homogeneracional y se apetece la mocedad en la satisfacción de una lascivia paidófila.

Su comisión supone la inmediata difamación del actor - de ahí su antigua instrumentalización política ${ }^{83}$-, pero también «pestilencia e otros tormentos en tierra donde se consiente» y daño social porque «ofenden a Dios nuestro Señor et infaman la tierra ${ }^{84}$. Cobran eficacia los perjuicios hacia determinados arquetipos de «peligrosidad social» como (representantes de farsas) ${ }^{85}$ o peregrinos ${ }^{86}$; gentes, en suma, sin ocupación «honesta» o en tránsito. También es manifiesto un componente xenófobo, pues son forasteros - italianos ${ }^{87}$ y castellanos ${ }^{88}$ los que traen el pecado a las ciudades ${ }^{89}$. Otro tanto sucede con las víctimas que, ocasionalmente, no son naturales del reino ${ }^{90}$ La marginalidad aviva, pues, la constelación de la sospecha y la inculpación.

El cuadro clínico de este ilícito obedece a desarreglos de personas inadaptadas con una elevada recidiva y un tracto temporal prolongado. El acoso puede realizarse en lugares distintos y consecutivos - a veces en despoblado o debajo

de Santiago de Compostela. A. Dioc. Z., Sección Histórico Jurídica, Procesos Criminales, C-10/16 (1581).

${ }^{80}$ A. Dioc. Z., Sección Histórico Juridica, Procesos Criminales, C-2/32 (1582).

${ }^{81}$ A. Dioc. Z., Secciôn Histórico Juridica, Procesos Criminales, C-19/1 (1560), C-30/33 (1570), C-10/16 (1581), C-4/14 (1573), C-2/32 (1582), C-20/8 (1565) \& C-76/18 (1599).

82 Menores de veinte anfos. A. Dioc. Z., Sección Histórico Juridica, Procesos Criminales, C-17/22 (1580) \& C-76/18 (1599).

83 James A. BRUNDAGE, «The politics of sodomy. Rex v. Pons Hugh de Ampurias (1311)», en Sex in the Middle Ages. A book of Essays, New York, 1991, pp. 239-46.

${ }^{84}$ El temor a que recayera el espectro de la maldición de Sodoma y Gomorra, y el peligro infamatorio que comportaba, coadyuvó a que en las Provincias Vascongadas no se suscitara en la actividad jurisdiccional de numerosos tribunales, en particular el lesbianismo. [Ifraki BAZÁN DIAZ, Delincuencia $y$ criminalidad en el Pais Vasco en la transición de la Edad Media a la Moderna, Vitoria, 1995, pp. 346-348]. Análogamente sucede en Valencia. Pablo Pérez Garcia, La comparsa de los malhechores. Valencia. 1479-1518, pp. 101-112.

Vid., a propósito del «morbus gallicus» (sifilis venérea), Jon ARRZZABALAGA, «Enfermedad y "rearme moral" en la Europa de finales del siglo XV: las pimeras percepciones del "mal francés" en Ferraray, Acta Historica et Archaeologica Mediaevalia, 16-17 (1995-96), pp. 135-36.

${ }^{85}$ A. Dioc. Z., Sección Histórico Juridica, Procesos Criminales, C-19/10 (1562).

86 A. Dioc. Z., Sección Histórico Jurídica, Procesos Criminales, C-10/22 (1573) \& C-17/22 (1580).

87 A. Dioc. Z., Sección Histórico Jurídica, Procesos Criminales, C-20/8 (1565) \& C-10/16 (1581).

88 A. Dioc. Z., Sección Histórico Juridica, Procesos Criminales, C-4/14 (1573).

${ }^{89}$ Francisco TOMÁs Y VALIENTE, «El crimen y pecado contra natura», p. 53

90 A. Dioc. Z., Sección Histórico Juridica, Procesos Criminales, C-52/13 (1562) \& C-2/32 (1582).

Actas del I Congreso de Historia de la Iglesia y el Mundo Hispánico

Hispania Sacra, 52 (2000) 
de un puente $e^{91}-$, o como sucede con los peregrinos compostelanos en sus diversas escalas de retorno (León, Logroño, Zaragoza y Tudela) $)^{92}$. Son apreciables los casos de varias tentativas frustradas con el mismo sujeto ${ }^{93} o$ con víctimas plurales, «tubiendo ajuntamiento y copula carnal con muchos hombres $»^{94}$. Así, cuando el actor se doblega a la presión en contra de su voluntad es el resultado de intentos persistentes ${ }^{95}$. Sólo en una proporción infima, al menos en apariencia, existe mutuo consentimiento y reciprocidad, pero siempre entre gente foránea de aspecto sospechoso y «muy mal atrapasados» ${ }^{96}$.

El objeto último pretende la consumación del acceso carnal - «cabalgar al deposante por el culo» ${ }^{97}$, «metiendoles su miembro viril por el vaso insolito" ${ }^{98}$-, aunque otras veces se recrimina meros tocamientos deshonestos del miembro viril ${ }^{99}$ o posturas obscenas - - $h$ ha hechado mano en sus partes vergonçosas y hechandoles las piernas encima, estando en posturas muy deshonestas»— ${ }^{100}$. La frustración — «no lo cavalgo ni pudo cumplir»—, se produce ante la interposición de testigos presenciales ${ }^{101^{\prime}}$.

La clave del grado de perfección o desviación radica en las circunstancias que rodean la acción. Una premisa frecuente descansa en la licencia para pernoctar en un domicilio particular, abusando de la buena fe del anfitrión, luego de una larga partida de naipes ${ }^{102}$, 0 , en el contexto de una relación laboral, tras ayudar a coser un sayo ${ }^{103}$; también coadyuvan circunstancias especiales como la condición de compatriotas en un país extraño ${ }^{104}$. De los testimonios recibidos se desprende que no era insólito que compartieran un mismo lecho dos ${ }^{105} \mathrm{o}$,

91 A. Dioc, Z., Sección Histórico Jurídica, Procesos Criminales, C-52/13 (1562).

92 A. Dioc. Z., Sección Histórica Juridica, Procesos Criminales, C-17/22 (1580).

93 A. Dioc. Z., Sección Histórico Juridica, Procesos Criminales, C-4/14 (1573) \& C-10/16 (1581).

94 A. Dioc. Z., Sección Histórico Juridica, Procesos Criminales, C-19/10 (1562) \& C-52/1 (1563).

${ }^{5}$ A. Dioc. Z., Sección Histórico Jurídica, Procesos Criminales, C-52/13 (1562).

96 «Les vio besar y abraçar, y despues de hecho esto vio que el uno dellos le echo mano a la bragueta del otro, y le saco sus verguenças (...) aguardando el negocio vio subir el uno encima del otro (...) entendiendo que se lo hasian uno al otro». A. Dioc. Z., Sección Histórico Juridica, Procesos Criminales, $\mathrm{C}-10 / 22$ (1573).

97 A. Dioc. Z., Sección Histónico Jurídica, Procesos Criminales, C-19/1 (1560), C-19/10 (1562) \& C-20/8 (1565).

9B A. Dioc. Z., Sección Histórico Jarídica, Procesos Criminales, C-52/1 (1563).

99 A. Dioc. Z., Sección Histbrico Jurídica, Procesos Criminales, C-20/8 (1565).

100 A. Dioc. Z., Sección Histórico Juridica, Procesos Criminales, C-76/18 (1599).

101 A. Dioc. Z, Sección Histórico Juridica, Procesos Criminales, C-30/33 (1570).

102 A. Dioc. Z., Sección Histórico Jurídica, Procesos Criminales, C-52/1 (1563).

103 A. Dioc. Z., Sección Histórico Juridica, Procesos Criminales, C-19/1 (1560), (1580).

104 A. Dioc. Z., Sección Histórico Jurídica, Procesos Criminales, C-10/22 (1573) \& C-17/22

${ }^{105}$ A. Dioc. Z., Sección Histórico Juridica, Procesos Criminales, C-19/10 (1562) \& C-2/32 (1582). 
incluso, tres personas diferentes ${ }^{106}$, lo que constituía una circunstancia propiciatoria y favorecedora de la proximidad física, porque «es usanza en su tierra dormir los hombres unos con otros como un hombre y una mujer» ${ }^{107}$. Además de las viviendas, donde se traiciona la amistad y la confianza del morador, otro microespacios frecuentados recaen en las instituciones asistenciales como el hospital de la Seo y el de la Verónica, ambos de Zaragoza ${ }^{\text {108 }}$, o la enfermería de Santas Cruces ${ }^{109}$. Algunos escenarios invaden la sacralidad de capillas bajo la advocación de San Tirso ${ }^{110}$ o de Nuestra Señora del Pilar ${ }^{111}$.

Las víctimas alegan indefensión al hallarse en estado de somnolencia ${ }^{112}$-la nocturnidad como manto de impudicia e impunidad ${ }^{113}$--, con clara inadvertencia del peligro, ante el cual oponen resistencia una vez que, sobresaltados, retornan al estado de vigilia, llegándose a enfrentamientos ${ }^{114}$, imprescindibles para exculparles de connivencia con el agresor ${ }^{155}$. Otros factores fortalecen la posición de desamparo de los sujetos pasivos, gestada no sólo en la menor edad, sino en una relación de confianza --manifiesta en el caso de los infantes de la Seo metropolitana, pajes o huérfanos ${ }^{116}$-, cupiendo beneficiarse de una relación jerárquica, como los enfermeros del Hospital de Nuestra Seffora de Gracia de Zaragoza, "officio de mucha confiança», en relación con tres criados que trabajan en la institución ${ }^{117}$.

Además del prevalimiento señalado, se recurre a todo tipo de promesas materiales, al punto de que sprocuro con alagos de tener parte con el deposante dixiendo le daria dones y aziendole promesas muchas y muy grandes porque cumpliese su voluntad» ${ }^{118}$. Cuando la respuesta es denegatoria y refractaria a

${ }^{106}$ A. Dioc. Z., Sección Histórico Jurídica, Procesos Criminales, C-19/1 (1560) \& C-52/1 (1563).

in Juan BLÁzQUEZ MigueL, La Inquisición en Cataluña. El Tribunal del Santo Oficio de Barcelona. $1487-1820$, p. 203.

108 A. Dioc. Z., Sección Histórico Jurídica, Procesos Criminales, C-10/22 (1573) \& C-10/16 (1581).

109 A. Dioc. Z., Sección Histórico Jurídica, Procesos Criminales, C-2/32 (1582).

110 A. Dioc. Z., Sección Histórico Jurídica, Procesos Criminales, C-19/10 (1562).

III A. Dioc. Z., Sección Histórico Juridica, Procesos Criminales, C-52/13 (1562).

112 A. Dioc. Z., Sección Histórico Jurídica, Procesos Criminales, C-19/10 (1562) \& C-2/32 (1582).

113 A. Dioc. Z., Sección Historico Juridica, Procesos Criminales, C-19/1 (1560) \& C-20/8 (1565).

114 «No soy bestia ni acostumbro hazer tal cosa». A. Dioc. Z., Sección Histórico Juridica, Procesos Criminales, C-19/1 (1560) (1560) \& C-2/32 (1582).

${ }^{115}$ A. Dioc. Z., Sección Histórico Jurídica, Procesos Criminales, C-19/1 (1560), C-19/10 (1562) \& $\mathrm{C}-20 / 8(1565)$.

115 A. Dioc. Z., Sección Histórico Juridica, Procesos Criminales, C-19/10 (1562), C-4/14 (1573) \& $\mathrm{C}-10 / 16(1581)$.

117 A. Dioc. Z., Sección Histórico Jurídica, Procesos Criminales, C-20/8 (1565).

11 A. Dioc. Z., Sección Histórico Jurídica, Procesos Criminales, C-19/1 (1560).

Actas del I Congreso de Historia de la Iglesia y el Mundo Hispánico Hispania Sacra, 52 (2000) 
las solicitudes pecaminosas, el solicitante puede reaccionar lanzando amenazas $^{119}$ o apelando a la violencia ${ }^{120}$; puede llegarse, en su caso, a un acuerdo paccionado mediando precio o contrato laboral como única forma de que desista en su empeño ${ }^{121}$.

La inspiración iusromanista de Las Partidas romperá con la tradición germánica en que se castigaba al sodomita con la castración, si bien perpetuará la pena capital, tanto del autor como del consentidor ${ }^{122}$, exculpando a los sodomizados en contra de su voluntad y a los menores de catorce af́os ${ }^{123}$, supuesto al que responden muchos justiciables. La severidad persistirá con la Pragmática de 1497 que los aboca inexorablemente a la hoguera, con la accesoria de la confiscación de bienes y dispersión de sus cenizas ${ }^{124}$.

En la última década del siglo XVI, Felipe II, para evitar la impunidad flexibiliza los medios de prueba ${ }^{125}$, la institucionaliza «por no concurrir en el averiguaciones de testigos con testes, siendo como es caso imposible probarse con ellos, por ser de gran torpeza y abominacion y de su naturaleza de muy difícil probanza» ${ }^{126}$. Los magistrados eclesiásticos, por su parte, son cautelosos si no se aportan pruebas suficientes, al entender que «dictum procuratorem fiscalem non bene probasse suam intentionem), decretando la excarcelación y libre absolución, afrontando las costas el querellante temerario ${ }^{127}$. De hecho, las falsas inculpaciones o la simulación del delito se revela como un vehículo idóneo para saldar enemistades vitandas ${ }^{128}$.

119 A. Dioc. Z., Sección Histórico hródica, Procesos Criminales, C-17/22 (1580).

120 «Estando en un campo (...) por fuerça tomo al dicho muchacho, y le desato los çaraguellos y lo hecho boca baxo en tierra, y con el miembro armado se le hecho encima y lo cavalgo, y de hecho tuvo ajuntamiento y copula camal (...) como si tuviera parte con una mugen). A. Dioc. Z., Sección Histórico Juridica, Procesos Criminales, C-30/33 (1570).

121 Un contrato por importe de tres ducados para que el agresor y su acompañante representaran comedias. A. Dioc. Z., Sección Histórico Juridica, Procesos Criminales, C-19/10 (1562).

122 Las Partidas, 7,21,1.

123 Las Partidas, 7,22,2

124 Juan Ramikez, Colección de Bulas y Pragmáticas de los Reyes Católicos, Madrid, 1503, fols. 148-149.

En el tribunal de la Inquisición de Valencia, la mayoría de los quemados en la hoguera por sodomía se registra entre 1616 y 1630 ; a partir de esta fecha la condena se atenúa, imponiéndoles galeras, azotes y/o destierro. Raphäel CARRASCo, Inquisición y represión sexwal en Valencia. Historia de los sodomitas (1565-1785), Barcelona, 1985.

125 Bartolomé BENNASSAR, «El modelo sexual: la Inquisición de Aragón y la represión de los pecados "abominables"), p. 298.

126 Francisco ToMÁS Y VALIENTE, «El crimen y pecado contra natura», p. 45.

127 A. Dioc. Z., Sección Histórico Juridica, Procesos Criminales, C-17/22 (1580).

128 El lugarteniente del zalmedina y juez ordinario de Zaragoza es hallado culpable de sobornar a tres vecinos de la ciudad para que indujeran a un enemigo manifiesto, oriundo del Bearn, a cometer 
Por contra, dada la repugnancia y censura que producen estas conductas, se aprecian dos pautas procesales: la aplicación de la tortura ${ }^{129}$, previo dictamen médico, sobre los autores o sus cómplices —que en la esfera inquisitorial había producido numerosas fricciones y conminatorias de la Suprema ${ }^{130}$, cuando las pruebas son semiplenas para esclarecer los hechos en evitación de la impunidad; de igual modo, y para poner freno a cualquier conato de alarma social, la actuación jurisdiccional se insta ex officio de inmediato y con ejecutividad, de forma que en algunas vistas se instruyen supuestos cometidos la noche anterior ${ }^{131}$.

Como línea argumentativa generalizada, los inculpados invocan ignorancia, arrepentimiento o ausencia de intencionalidad dolosa: «no conosce haver offendido a Dios gravemente, al qual pide perdon por ello, y se hecho en braços del dicho senyor officialy. Se ruega en la confesión un trato benigno alegando rusticidad y se solicita penitencia. Otro medio de atenuar el castigo consiste en alegar que los intentos se habían gestado en sueños, por lo que no eran plenamente conscientes de sus actos, o que.la penetración fue parcial sin provocar la eyaculación ${ }^{132}$, aunque la erección - «miembro drecho»o «miembro armado» ${ }^{133}-$ sea casi siempre una realidad.

Cuando existen elementos de convicción suficientes, el tribunal eclesiástico de Zaragoza lo castiga según práctica consuetudinaria - «ut moris est»-con la flagelación pública, exilio del arzobispado - no superior a seis antos-y la accesoria en costas, puniéndose con severidad la reincidencia y la comisión in sacro $^{134}$. No obstante, no se contempla la frustratio como atenuante, como lo demuestra una causa en que el reo es condenado a doscientos latigazos, destierro de la diócesis - su quebrantamiento implica una tanda equivalente de latigazos-y el pago de las expensas ${ }^{135}$.

este crimen, de modo que pudiera fingir que los prendia in fraganti. A. Dioc. Z., Sección Histórico Jurídica, Procesos Criminales, C-33/12 (1581).

El pensamiento ortodoxo, que equipara la penetración homosexual con el adulterio, agrava la responsabilidad del sujeto activo por inducir a un tercero a la transgresión. Pedro Badenas DE LA PENA, "El diablo y el sexo en el monacato eslavo", Codex Aqvilarensis, 11 (1994), p. 81.

129 Bartolomé BENNASSAR, «El modelo sexual: la Inquisición de Aragón y la represión de los pecados "abominables" "), pp. 313-314.

${ }^{130}$ Michèle Escamlla-Colf́, Crimes et chatiments dans l'Espagne Inquisitoriale, Paris, 1992, vol. II, pp. 283-84.

${ }_{131}$ A. Dioc. Z., Sección Histórico Juridica, Procesos Criminales, C-10/16 (1581) \& C-2/32 (1582).

132 «Se desataco y abaxo sus calças, y tubiendo su miembro derecho se asio con uno que dormia con el y quiso tener acceso camal y de drecho le metio parte de un miembro en el rabom. A. Dioc. Z., Sección Histórico Juridica, Procesos Criminales, C-52/1 (1563).

133 A. Dioc. Z., Sección Histórico Jurídica, Procesos Criminales, C-19/10 (1562) \& C-10/16 (1581).

134 A. Dioc. Z., Sección Histórica Juridica, Pracesos Criminales, C-52/13 (1562).

135 "Ut fustibus et flagelis ducentis bapuletum. A.Dioc.Z., Sección Histórico Jurídica, Procesos Criminales, C-19/1 (1560).

Actas del I Congreso de Historia de la Iglesia y el Mundo Hispánico

Hispania Sacra, 52 (2000) 


\subsection{Bestialismo \& zoofilia: corruptio pessima}

La zoofilia - fruto, para algunos, de la «mitología zoomórfica» ${ }^{136}$ - o ("pecado bestial», es uno de los medios más vejatorios y degradantes de la dignidad de la persona ${ }^{137}$. Desde la perspectiva eclesial estos pecadores desatan sus más bajos instintos en detrimento de la fe «que como fiel y catholico christiano tiene dado y prometido a nuestro Redemptor Jesu Christo y a la Santa Madre Yglesia Catolica, en grande perdicion y destruycion y dampnacion de su alma y conciencia, y en menosprecio y desacato de los preceptos y mandamientos de Dios» ${ }^{138}$; o bien, «con animo iniquo yndimoniado, no trujendo quenta con quera cristiano y que los buenos cristianos no se an de emplear si no en serbir a Nuestro Sennor pues para ello somos criados» ${ }^{139}$. Bajo estos parámetros, la comisión en días festivos envilece la acción, «en especial los domingos y fiestas que para ello estan establecidos para yr a oyr los divinos oficios» ${ }^{140}$.

Los procesados suelen ser mozos de edades comprendidas entre trece y quince años ${ }^{141}$; cuando se instruyen diligencias contra adultos, acreditan «publica deshonestas» o comportamientos antisociales (amenazas) e impíos (desprecio de sacramentos, ayunos y abstinencias, juramentos y blasfemias) ${ }^{142}$. Su comisión tiene como escenario preferente, aunque no exclusivo, el ámbito rural (Villahermosa del Campo, Zuera, Leciñena, Monzalbarba, Ainzón, Alcaniiz ${ }^{143}$ ), de ahí que estén adscritos a la actividad agropecuaria como agricultores o mozos de labor ${ }^{144}$, sin omitir a algunos artesanos fabriles ${ }^{145}$. Como sucedía con la sodomía, integra distintas jurisdicciones, con un indiscutible protagonismo de la inquisitorial, siendo mucho más remisa la magistratura eclesial, que manifiesta también un ligero desfase, puesto que el primer procesado conocido, un mozo del arciprestazgo de Daroca, no comparece hasta 1561 (ver cuadro).

136 Ricardo García CáRCEL, Herejia y Sociedad en el siglo XVI. La Inquisición de Valencia (15301609), p. 289.

137 Joyce E. SALISBUrY, «Bestiality on the Middle Ages», en Sex in the Middle Ages. A book of Essays, New York, 1991, pp. 173-186.

138 A. Dioc. Z., Sección Histórico Juridica, Procesos Criminales, C-29/13 (1564).

139 A. Dioc. Z., Sección Histórico Juridica, Procesos Criminales, C-27/30 (1571).

140 A. Dioc. Z., Sección Histórico Jurídica, Procesos Criminales, C-27/30 (1571).

${ }^{141}$ A. Dioc. Z., Sección Histórico Juridica, Procesos Criminates, C-2/7 (1584) \& C-2/25 (1578). (1588).

142 A. Dioc. Z., Sección Historico Jurtdica, Procesos Criminales, C-27/14 (1574) y C-35/20

${ }^{143}$ A. Dioc. Z., Sección Histórico Juridica, Procesos Criminales, C-2/27 (1561), C-19/40 (1564), C-27/14 (1574), C-2/25 (1578), C-2/7 (1584) \& C-35/20 (1588).

144 A. Dioc. Z., Sección Histórico Juridica, Procesos Criminales, C-19/40 (1564), C-2/25 (1578) y C-27/14 (1574).

${ }^{145}$ A. Dioc. Z., Sección Histórico Juridica, Procesos Criminales, C-35/20 (1588). 


\begin{tabular}{|c|c|c|c|}
\hline Periodo & Inquisición & Iglesia & Total \\
\hline $1541-1550$ & 0 & 0 & 0 \\
\hline $1551-1560$ & 2 & 0 & 2 \\
\hline $1561-1570$ & 5 & 3 & 51 \\
\hline $1571-1580$ & 48 & 3 & 51 \\
\hline $1581-1590$ & $(\ldots)$ & 2 & $(\ldots)$ \\
\hline $1591-1600$ & $(\ldots)$ & 0 & $(\ldots)$ \\
\hline
\end{tabular}

La acción típica realiza el acceso por vía anal mediante la inmissio penis, resultando inequívoco en la práctica totalidad de los sumarios la prosecución de la cópula carnal: «como si fuera muger en natura humana engendrada» ${ }^{146}$; «la cabalgo por su natura, y asi tubo acceso carnal... como acostumbran tener los hombres con las mugeres) ${ }^{147}$; «saco su miembro armado y lo puso dentro de la natura de la dicha mula, de suerte que metiendolo y sacandolo llego a tener ajuntamiento y copula carnal consumada ${ }^{148}$, etc. Cabe la frustración cuando un vecino conmina a un menor con delatarlo a su padre ${ }^{149}$. Un hecho distinto es que, a efectos de la consumación, se aduzca el desistimiento poco antes de la eyaculación, que nunca se aprecia como atenuante de la perversión: «por la parte posterior a las anças, y para poder llegar a tener el dicho acto nefando... y poder llegar con su miembro a la natura del dicho animal, tomo un banco, y metiendo de pies encima de aquel llego con el dicho su miembro armado y abraçando la dicha yegua por las anças se lo metio y puso a dicha yegua por natura, y teniendolo dentro començo a meter y sacarlo, habiendo el movimiento que se requiere para la consumacion de semejante acto nefando, y quando el confesante vio y conocio que llegava a consumar el dicho acto, saco su miembro de la natura de la dicha yegua y vertio la simiente de fuera en el suelo» ${ }^{150}$.

La privacidad de estos accesos dificulta la obtención de pruebas de «tan vil y bajo comportamiento", los imputados gustan de realizarlo en recintos cerrados como las caballerizas ${ }^{151}$, abrevaderos ${ }^{152}$ o corrales ${ }^{153}$. Cuando no se dispone de

\footnotetext{
146 A. Dioc. Z., Sección Histórico Jurídica, Procesos Criminales, C-29/13 (1564).

${ }^{147}$ A. Dioc. Z., Sección Histórico Jurídica, Procesos Criminales, C-27/30 (1571).

148 A. Dioc. Z., Sección Histórico Jurídica, Pracesos Criminales, C-27/14 (1574).

149 A. Dioc. Z., Secclón Histórico Juridica, Procesos Criminales, C-2/7 (1584).

150 A. Dioc. Z., Sección Histónico Juridica, Procesos Criminales, C-2/25 (1578).

151 A. Dioc. Z., Sección Histórico Juridica, Procesos Criminales, C-27/30 (1571) y C-2/25 (1578).

152 A. Dioc. Z., Sección Histórico Jurídica, Procesos Criminales, C-27/14 (1574).
} 
«espacios de retraimiento» y se lleva a cabo de modo incidental, cualquier locus es adecuado, como una covachuela que sirve de cobijo ante una lluvia copiosa ${ }^{154}, o$ un descampado «açia el monte en una parte y lugar secreto donde no havia concursso de gente» ${ }^{155^{\circ}}$, lo que no siempre se logra por inadvertencia o escasa cautela, como la actuación perpetrada en un pastizal cerca de un tapiado en la romería de la Virgen de mayo, imbuido de la placidez que reporta la digestión de la pitanza ${ }^{156}$.

La repudiable sensualidad, nacida de la inspiración diabólica — «con animo iniquo yndimoniado", «endemoniado y diabolico proposito y pecado", "tentado del enemigo malo, le vino gana y apetito sensual de tener accesso carnal ${ }^{157}$ - se desata o se halla muy condicionada por encontrarse el animal dentro del campo visual del actor ${ }^{158}$. Es sintomático, por ello, que la ejecución material del «torpe apetito» no presente la nocturnidad típica de otros ilícitos, prefiriéndose el mediodia ${ }^{159}$, el segmento vespertino ${ }^{160}$ o la hora crepuscular ${ }^{161}$.

Los animales más comunes - propiedad del procesado, sus consanguíneos o un tercero con el que mantiene relación laboral--, pertenecen mayoritariamente a la familia de los équidos $(85 \%)$ - mulas ${ }^{162}$, burras $^{163}$, asnas ${ }^{164}$ y yeguas ${ }^{165}$-., aunque también tengan una representación incidental los cánidos -perras de grandes dimensiones ${ }^{166}$, especies frecuentadas en otros ámbitos ${ }^{167}$.

153 A. Dioc. Z., Sección Histórico Juridica, Procesos Criminales, C-2/25 (1578).

154 A. Dioc. Z., Sección Histórico Juridica, Procesos Criminales, C-2/7 (1584).

iss A. Dioc. Z., Sección Histórico Jurídica, Pracesos Criminales, C-27/14 (1574).

156 A. Dioc. Z., Sección Histórico Jurídica, Procesos Criminales, C-19/40 (1564).

Ist A. Dioc. Z., Sección Histórico Jurídica, Procesos Criminales, C-27/30 (1571), C-29/13 (1564) y C-2/25 (1578)

158 «Haviendose assentado en el suelo cubierto con su capote para defenderse del agua que a la sazon llovia, estando la borrica apartada deste conffessante», a una distancia de cincuenta o sesenta pasos, udio gana de tener ajuntamiento carnal con la dicha borrica, y poniendo en execucion su torpe apetito, se fue para la dicha borrica que estaba en una hondura paciendo, y llego a ella por las ancas con su miembro armado con intencion de consumar dicha su torpezay. A. Dioc. Z., Sección Histórico Jurídica, Procesos Criminales, C-2/7 (1584) \& C-19/40 (1564).

${ }_{159}$ A. Dioc. Z., Sección Histórico Juridica, Procesos Criminales, C-27/14 (1574) \& C-2/7 (1584).

${ }^{160}$ Entre las cinco y las seis de la tarde. A. Dioc. Z., Sección Histórico Jurídica, Procesos Criminales, C-19/40 (1564)

${ }^{161}$ A. Dioc. Z., Sección Historico Juridica, Procesos Criminales, C-2/25 (1578).

162 A. Dioc. Z., Sección Histórico Jurídica, Procesos Criminales, C-27/14 (1574).

163 A. Dioc. Z., Sección Histórico Jurídica, Pracesos Criminales, C-2/27 (1561), C-27/30 (1571), C-2/7 (1584) y C-35/20 (1588).

${ }^{164}$ A. Dioc. Z., Sección Histórico Juridica, Procesos Criminales, C-19/40 (1564).

${ }^{165}$ A. Dioc. Z., Sección Histórico Jurídica, Procesos Criminales, C-2/25 (1578).

166 A. Dioc. Z., Sección Histórico Jurídica, Procesos Criminales, C-29/13 (1564).

${ }^{167}$ En Valencia se registra un predominio de burras y perras, y en menor número mulas, cabras y cerdas. Ricardo Garcia CARCEL, Herejia y Sociedad en el siglo XVI. La Inquisición de Valencia (1530 1609), p. 291. 
La repulsa social que recae sobre estos comportamientos lo convierten en imprescriptibles, pudiendo ventilarse desviaciones producidas cinco o seis años atrás ${ }^{168}$, lo que contribuye a su ardua persecución. Por esta razón, es crucial la existencia de testigos oculares - que suelen ser muy explícitos y un punto morbosos en sus naturalistas descripciones ${ }^{169}$, de otro modo la frustración del fiscal es manifiesta ante su impotencia por demostrar un coito tan vil de los que existe constancia, pero que las personas «no tienen cara para deposar, y asi no las osan deposan ${ }^{170}$. Por lo común, se adoptan unas mínimas precauciones para obtener la impunidad, no soliendo el comisor jactarse de su acción ante distintas personas, las cuales testificarán en su contra ${ }^{171}$.

En efecto, el castigo ejemplar se enfrenta a las dificultades derivadas de su privacidad y apartamiento en que acostumbra a cometerse este apostema, por lo que un medio eficaz, aunque muy infrecuente, es el prendimiento in fraganti realizado por lo común por el justicia y el juez ordinario de la población ${ }^{172}$. La confesión judicial no siempre es espontánea, sino que obedece a la presión ejercida paterna ${ }^{173}$.

Si nos atenemos a la tradición bíblica, la pena de muerte fulminaba a los que copulan o se acoplan con una bestia, fuesen hombre o mujer ${ }^{174}$, mereciendo la misma suerte el animal involucrado, a fin de que sne duret memoria allius crimen ${ }^{175}$. La justicia eclesiástica, cuando concurren todos los elementos del tipo, solicita la máxima pena por ahorcamiento, como inapelablemente señala una sentencia condenatoria: «ad mortem naturalem, videlicet, ad infurcandum in furca cum capistro in colo taliter quos suos dies extremos et naturales fincant ${ }^{176}$. La dureza mostrada por los órganos inquisitoriales depende de cir-

16. A. Dioc. Z., Sección Histórico Juridica, Procesos Criminales, C-2/27 (1561).

169 "Tomo la dicha asna de donde estaba, y la traxo y la puso dentro del dicho tapiado, dentro de una foja, junto a unas tapias, y le cubrio la cabeça con una capa, y se echo el dicho reo y criminoso encima de la asna, y tubo ajuntamiento con ella y la conocio camalmente»; watandose la dicha perra al pescuezo, piernas y braços, $y$ a otra parte a el bien visto para aquella con mas facilidad conocer»; «metiendo la dicha mula entre dos ribaçillos las ancas para sy, se subio encima de una piedra para allegar con la mitad del cuerpo a las ancas de la dicha mulas. A. Dioc. Z, Sección Histórico Juridica, Procesos Criminales, C-19/40 (1564), C-29/13 (1564) \& C-27/14 (1574).

170 A. Dioc. Z., Sección Histórico Juridica, Procesos Criminales, C-27/30 (1571).

171 A. Dioc. Z., Sección Histórico Jurídica, Procesos Criminales, C-35/20 (1588).

t7 A. Diac. Z., Sección Histónico Jurídica, Procesos Criminales, C-19/40 (1564).

173 A. Dioc. Z., Sección Histórico Jurídica, Procesos Criminales, C-2/7 (1584).

174 Exodo, 22,19 y Levítico, 20,15-16.

173 "Para amortiguar la remembrança del fecho». Las Partidas, 7,21,2. Cfr., en el concierto europeo, E. P. Evans, The criminal prosecution and capital punishment of animals, London, 1987.

176 A. Dioc. Z., Sección Histórico Juridica, Procesos Criminales, C-19/40 (1564).

Actas del I Congreso de Historia de la Iglesia y el Mundo Hispánico

Hispania Sacra, 52 (2000) 
cunstancias y sedes ${ }^{177}$ - la condenas a vivicombustión son casi despreciables en Barcelona (1\%), moderadas en Valencia (22\%) y acusadas en Zaragoza $(57 \%)^{178}$-, aunque tiende a consolidarse el destierro o, ulteriormente las galeras, siempre con la ignominia de los azotes ${ }^{179}$.

En virtud de la discrecionalidad judicial, algunos magistrados desisten de aplicar el rigor iuris, al apreciar diversas atenuantes como la confesión espontánea, la minoría de edad, la contricción y el arrepentimiento ${ }^{180}$. Esta benignidad canónica se traduce — al menos en un caso - en un confinamiento domiciliario y una prestación social en favor de la comunidad por espacio de tres años -el primero perentorio y los dos restantes al arbitrio arzobispal- en el Hospital General de Zaragoza, cuyos trabajos le serán asignados por la Curia, calculándose en veinte escudos los gastos que deberá sufragar para su mantenimiento; como accesoria se le señala que todos los viemes del año habrá de rezar siete salmos penitenciales con su letanía, y satisfará las costas procesales ${ }^{181}$.

En otro fallo distinto, el instructor confina al inculpado dentro del término de la ciudad de Zaragoza bajo la custodia de su progenitor, no pudiendo salir sin licencia expresa del vicario general ${ }^{182}$. En este sentido, una de las más eficaces células de control es la familia, ya que en este tipo de delitos es reo de infamia el apellido, con lo que la solución más plausible para el linaje consistía en su reclusión domiciliaria o monástica, profilaxis más apetecida que la solución penal, que siempre conducía a un «honor en entredicho». Actúa, pues, la reprensión doméstica preventiva - el Estado no irrumpe en la intimidad hasta fines del siglo XV- y activa mecanismos de exclusión para no dafíar la línea sucesoria ni la transmisión de las herencias ${ }^{183}$.

177 Nos atenemos a los datos compulsados para el período 1566-1620 por Raphăel CARRASCO, «Le châtiment de la sodomie sous l'Inquisition (XVI-XVIle siècle)), p. 61 .

178 Los niveles varian según las fuentes y cronologías estudiadas, ya que otros trabajos lo sitúan en un 41\%. Bartolomé BENNASSAR, «El modelo sexual: la Inquisición de Aragón y la represión de los pecados "abominables"”, p. 317.

179 Ricardo GARCía CARCEL, Herejía y Saciedad en el siglo XVI. La Inquisición de Valencia (I5301609), p. 289; Juan BlÁzQuez Miguel, La Inquisición en Cataluña. El Tribunal del Santo Oficio de Barcelona. 1487.1820 , p. 209, y Francisco TOMÁS Y VALIENTE, «El crimen y pecado contra natura», p. 53.

${ }^{180}$ Michèle EscamiLla-CoĹ́n, Crimes et chatiments dans l'Espagne Inquisitoriale, Paris, 1992 , vol. II, pp. $285-86$.

181 A. Dioc. Z., Sección Histórico Juridica, Procesos Criminales, C-2/25 (1578).

182 A. Dioc. Z., Sección Histórico Juridica, Procesos Criminales, C-35/20 (1588).

183 Lausa IKINs STERN, The Criminal Law System of Medieval and Renaissance Florence, London, 1994, p. 224

Actas del I Congreso de Historia de la Iglesia y el Mundo Hispánico

Hispania Sacra, 52 (2000) 